\title{
PARÂMETROS GENÉTICOS DE CARACTERES RELACIONADOS À TOLERÂNCIA À DEFICIÊNCIA HÍDRICA EM MILHO TROPICAL ( $\left.{ }^{1}\right)$
}

\author{
TASSIANO MAXWELL MARINHO CÂMARA $\left({ }^{2 *}\right)$; DYEME ANTÔNIO VIEIRA BENTO $\left({ }^{2}\right)$; \\ GEOVANI FERREIRA ALVES $\left({ }^{2}\right)$; MATEUS FIGUEIREDO SANTOS $\left({ }^{2}\right)$; \\ JOSÉ UBIRAJARA VIEIRA MOREIRA $\left({ }^{2}\right)$; CLÁUDIO LOPES DE SOUZA JÚNIOR $\left({ }^{*}\right)$
}

\begin{abstract}
RESUMO
A seleção de caracteres relacionados à tolerância à deficiência hídrica em milho tem sido objeto de interesse em programas de melhoramento, principalmente em virtude da ineficiência da seleção para produzir grãos nessas condições. O objetivo deste trabalho foi estimar parâmetros genéticos em duas populações de milho tropical. Foram avaliadas duas populações (denominadas D e U) com 256 progênies $\mathrm{F}_{2: 3}$, no delineamento em látice $16 \times 16 \mathrm{em}$ sete ou nove ambientes e densidade populacional de 62.500 plantas $\mathrm{ha}^{-1}$. Diferenças significativas foram constatadas entre progênies $(\mathrm{P})$, ambientes $(\mathrm{A})$ e para a interação $\mathrm{P}$ x A em ambas as populações. Os coeficientes de herdabilidade em nível de médias de progênies variaram entre $73,52 \%$ para prolificidade na população D e 95,88\% para florescimento feminino (FF) na população U. No caráter produção de grãos (PG) houve correlação genética significativa nas populações U e D, respectivamente, com prolificidade $(0,79$ e 0,88$)$ e florescimento feminino $(-0,76$ e $-0,44)$; na população U com florescimento masculino $(-0,74)$ e; na população D com stay-green $(-0,50)$. Não foi constatada correlação genética significativa entre PG e intervalo entre florescimentos (IF). Os parâmetros genéticos estimados sugerem que a utilização de índices de seleção que incluam, além de PG, caracteres como prolificidade, FF e SG na seleção de progênies sob condições normais de umidade, poderia propiciar o desenvolvimento de material com alta produtividade e boa tolerância a estresses hídricos.
\end{abstract}

Palavras-chave: Estresse hídrico, estresse abiótico, correlação, produção de grãos, stay-green.

\section{ABSTRACT \\ GENETIC PARAMETERS OF DROUGHT TOLERANCE RELATED TRAITS IN TROPICAL MAIZE}

The selection of drought tolerance related traits in maize has been object of interest in improvement programs, mainly in function of the selection inefficiency for grain yield on these conditions. The objective of this work was to estimate genetic parameters in two populations of tropical maize. Two populations (called D and $\mathrm{U}$ ) with $256 \mathrm{~F}_{2: 3}$ progenies had been evaluated in a 16x16 simple lattice, in seven and nine environments with population density of 62,500 plants ha ${ }^{-1}$. Significant differences were observed among line $(\mathrm{P})$, environments $(\mathrm{A})$ and for the $\mathrm{P} \times \mathrm{A}$ interaction in both populations. The heritability coefficients at progenies level average had varied between $73.52 \%$ for prolificacy in population D and $95.88 \%$ for female flowering (FF) in population U. Grain yield (PG) presented significant genetic correlation in populations $U$ and $D$, respectively, with prolificacy $(0,79$ and 0.88$)$ and female flowering $(-0,76$ and $-0,44)$; in population $U$ with male flowering $(-0.74)$ and; in population D with stay-green (-0.50). No genetic correlation was observed between PG and anthesis-silking interval (IF). Estimated of genetic parameters suggest that the use of selection indices that include, besides PG, characters as prolificacy, FF and SG in the selection process under conditions of normal water supply, could lead to the development of cultivars with high grain yield and good drought tolerance.

Key words: abiotic stress, grain yield, stay-green.

$\left({ }^{1}\right)$ Parte da tese submetida pelo primeiro autor como cumprimento parcial dos requisitos para a obtenção do título de Doutor em agronomia, área de concentração em genética e melhoramento de plantas. Recebido para publicação em $1 .^{\circ}$ de novembro de 2006 e aceito em $1 .^{\circ}$ de junho de 2007.

$\left({ }^{2}\right)$ Departamento de Genética, Escola Superior de Agricultura “Luiz de Queiroz", Universidade de São Paulo, Avenida Pádua Dias, 11, Caixa Postal 83, 13400-970, Piracicaba (SP). E-mail: clsouza@esalq.usp.br ( ${ }^{*}$ ) Autor correspondente. 


\section{INTRODUÇÃO}

Na maioria das áreas cultivadas com milho no mundo, a ocorrência de seca ou períodos de estresse hídrico são fatores abióticos causadores de substanciais reduções na produtividade. No Brasil, as áreas cultivadas com milho são predominantemente desenvolvidas sem irrigação e mesmo em anos regulares de precipitação pluvial observam-se, normalmente, perdas na produção em virtude de períodos de estiagem denominados "veranicos". Fatores abióticos, principalmente a seca, fizeram com que o país deixasse de colher mais de 15 milhões de toneladas de grãos de milho entre 1996 e 2002; em algumas regiões, observaram-se perdas superiores a $92 \%$ e $88 \%$, respectivamente, nas safras de 1998 e 2001 (IbGe, 2004). Desse modo, é necessário priorizar o desenvolvimento de cultivares tolerantes à deficiência hídrica nos programas de melhoramento de milho.

Muitos programas de melhoramento não têm tido sucesso no desenvolvimento de cultivares tolerantes ao déficit hídrico. A seleção para produção de grãos sobre estresse hídrico tem sido considerada ineficiente em vista da alta proporção da variância ambiental em relação à genética, o que reduz a herdabilidade do caráter e dificulta a seleção de genótipos superiores. O melhoramento convencional para produção em condições de déficit hídrico é moroso e laborioso, visto que as condições experimentais devem ser cuidadosamente manejadas. Ainda, o aumento do estresse de umidade induz a redução na produção, sendo dependente de dois fatores com efeitos combinados, ou seja, a suscetibilidade da planta à seca e a expressão do potencial produtivo, tanto sob estresse, quanto em condições normais, fazendo com que a seleção se torne mais complexa. Na maioria dos países tropicais, há apenas uma época do ano em que não ocorrem chuvas, e se pode praticar seleção para tolerância à seca, o que aumenta o tempo gasto no desenvolvimento e na liberação de cultivares tolerantes ao estresse hídrico (Ribaut et al., 1997). Desse modo, faz-se necessária a seleção de caracteres que estejam relacionados à tolerância ao déficit hídrico e que possam ser manipulados em experimentos na ausência de déficits hídricos.

Inúmeros autores relatam que os principais caracteres a serem considerados em programas de melhoramento visando à tolerância a déficits hídricos são: prolificidade (número de espigas por planta); intervalo entre florescimentos masculino e feminino; número de ramificações do pendão; e senescência retardada das folhas e colmo (stay-green). Esses caracteres são de herdabilidade elevada, correlacionados com a produção de grãos e passíveis de serem avaliados fenotipicamente em larga escala (Ribaut et al., 1996; Agrama e Moussa, 1996; BänZINGER et al., 2000; KAMARA et al., 2003). No Brasil, trabalhos abordando estudo de caracteres com ênfase ao melhoramento para estresse hídrico têm sido pouco relatados, restringindo-se apenas aos caracteres prolificidade e intervalo entre florescimentos (SANTOS et al., 2003; DURÃES et al., 2004). Assim, este trabalho teve por objetivo estimar parâmetros genéticos de caracteres relacionados à tolerância ao déficit hídrico em duas populações de milho tropical.

\section{MATERIAL E MÉTODOS}

Foram utilizadas duas populações, constituídas de 256 progênies $\mathrm{F}_{2: 3}$ cada uma. A primeira população, denominada " $U$ ", foi obtida do cruzamento entre as linhagens endogâmicas L14-04B e L08-05F. A outra população, denominada " $D$ ", foi obtida do cruzamento entre as linhagens endogâmicas L20-01F e L02-03D. Detalhes sobre as populações que deram origem às linhagens são apresentados por SOUZA JÚNIOR et al. (1993) e MANGOLIN et al. (2004). Essas linhagens são contrastantes para inúmeros caracteres agronômicos e foram cruzadas dando origem à geração $F_{1}$ que autofecundada, originou a população $\mathrm{F}_{2}$. Plantas dessa população foram posteriormente autofecundadas, dando origem às progênies $F_{2: 3}$. Para aumentar o número de sementes disponíveis, cada progênie $F_{2: 3}$ foi plantada em linha, realizando-se cruzamentos entre plantas dentro das linhas de forma que cada planta participasse uma única vez como genitor masculino ou feminino. No presente trabalho todo o material utilizado foi proveniente de milho tropical.

As 256 progênies $F_{2: 3}$ provenientes de cada uma das populações $\mathrm{D}$ e $\mathrm{U}$ foram avaliadas em nove e sete ambientes, respectivamente, entre os anos agrícolas de 2001/2002 e 2003/2004. A combinação ano agrícola x local correspondeu a um ambiente. As progênies da população $D$ foram avaliadas nas Estações Experimentais Fazenda Areão, Fazenda Caterpillar, nos anos agrícolas de 2001/2002, 2002/ 2003 e 2003/2004; no Departamento de Genética da ESALQ/USP, nos anos agrícolas de 2002/2003 e 2003/2004 e na Fazenda Anhembi no ano agrícola de $2003 / 2004$. As progênies da população U foram avaliadas nas Estações Experimentais Fazenda Areão, no ano agrícola de 2002/2003, na Fazenda Caterpillar, no Departamento de Genética da ESALQ/ USP e na Fazenda Anhembi, nos anos agrícolas de 2002/2003 e 2003/2004. Empregou-se o delineamento experimental de blocos incompletos em látice simples $16 \times 16 \mathrm{com}$ duas repetições. As parcelas foram constituídas por uma linha de 4,0 m com 0,8 m entre 
linhas e $0,2 \mathrm{~m}$ entre plantas. Foram semeadas 50 plantas por parcela sendo realizado o desbaste cerca de 30 dias após o plantio, deixando-se 20 plantas por parcela, o que correspondeu a uma densidade de 62.500 plantas ha ${ }^{-1}$. Todos os experimentos foram plantados e colhidos manualmente. Quando necessário, foi fornecida irrigação complementar aos experimentos desenvolvidos nas estações experimentais do Departamento de Genética da ESALQ/USP e da Fazenda Anhembi.

Dados referentes à produção de grãos (gramas planta $\left.^{-1}\right)$, umidade (\%), número de espigas por parcela (espigas parcela $\left.{ }^{-1}\right)$, estande (plantas parcela $\left.{ }^{-1}\right)$, florescimentos feminino e masculino (dias), número de ramificações do pendão (número pendão ${ }^{-1}$ ) e staygreen (nota), foram tomados em todos os experimentos. A produção de grãos (PG) de cada parcela foi ajustada para estande médio e umidade de $15,0 \%$. A prolificidade (PROL) foi obtida com o número de espigas por parcela dividido pelo estande. Os florescimentos feminino (FF) e masculino (FM) foram obtidos como o número de dias do plantio até que $50 \%$ das plantas de cada parcela tivessem, respectivamente, antese e estilo-estigmas visíveis. $\mathrm{O}$ intervalo entre florescimentos (IF) foi calculado como a diferença, em dias, entre o florescimento feminino e o florescimento masculino. O número de ramificações do pendão (NRP) correspondeu ao número de ramificações primárias de cinco plantas competitivas da parcela. Stay-green (SG) foi avaliado cerca de 120 dias após a semeadura, com base em uma escala de notas variando de 1 a 5 , na qual 1 corresponde a plantas com todas as folhas acima da primeira espiga e pelo menos duas folhas verdes abaixo da primeira espiga e 5 , a plantas com todas as folhas secas. Em cada parcela foram avaliadas cinco plantas competitivas, sendo a média utilizada nas análises. Em função de os cruzamentos terem diferentes níveis de maturação, na análise de stay-green foi utilizado o caráter florescimento feminino como covariável a fim de corrigir essas diferenças de maturação visando à análise mais precisa do caráter. Os caracteres foram avaliados em sete ambientes entre os anos agrícolas de 2002/2003 e 2003/2004 à exceção dos caracteres PG e PROL na população $\mathrm{D}$, que também foram avaliados no ano agrícola de 2001/2002 nas estações experimentais Fazenda Areão e Fazenda Caterpillar, perfazendo o total de nove ambientes de avaliação para esses dois caracteres nesta população.

As análises de variância foram inicialmente realizadas para cada caráter em cada ambiente e, posteriormente, feita a análise conjunta de variância por caráter. Na análise conjunta, foi considerado o modelo matemático aleatório dado por:

$$
y_{i j k l}=\mu+p_{i}+r_{j(l)}+b_{k(j l)}+a_{l}+(p a)_{i l}+e_{i j k l}
$$

em que: $y_{i j k l}$ é o valor observado da progênie $i$, na repetição $j$, no bloco $k$, no ambiente $l ; \mu$ é a média geral do experimento; $p_{i}$ é o efeito da progênie $i(i=$ $1,2, \ldots 256) ; r_{j}$ é o efeito da repetição $j(j=1,2)$ dentro do ambiente $l ; b_{k(j))}$ é o efeito do bloco $k(k=1,2, \ldots, 16)$ dentro da repetição $j$, dentro do ambiente $l ; a_{1}$ é o efeito do ambiente $l(l=1,2, \ldots 7$ ou $l=1,2, \ldots 9) ;(p a)_{i l}$ é o efeito da interação progênies $\mathrm{x}$ ambientes; $e_{i j k l}$ é o erro associado à observação $y_{i j k l}$.

Os valores dos quadrados médios da análise de variância conjunta foram utilizados para estimar os componentes das variâncias de progênies $\left(\sigma_{P}^{2}\right)$, interação progênies $x$ ambientes $\left(\sigma_{P A}^{2}\right)$, resíduo $\left(\sigma_{E}^{2}\right)$ e fenotípica média $\left(\sigma_{\bar{F}}^{2}\right)$. Os coeficientes de herdabilidade no sentido amplo ao nível de médias de progênies $\mathrm{F}_{2: 3}\left(h_{\bar{p}}^{2}\right)$, foram estimados por:

$$
\hat{h}_{\bar{p}}^{2}=\frac{\hat{\sigma}_{p}^{2}}{\hat{\sigma}_{\bar{F}}^{2}}
$$

Os coeficientes de correlações genéticas $\left(\hat{r}_{G x y}\right)$ e fenotípicas $\left(r_{\bar{F} x y}\right)$ entre dois caracteres $x$ e $y$, foram estimados como:

$$
\begin{aligned}
& \hat{r}_{G x y}=\frac{C \hat{O} V_{P x y}}{\sqrt{\hat{\sigma}_{P x}^{2} \hat{\sigma}_{P y}^{2}}} \\
& \hat{r}_{\bar{F} x y}=\frac{C \hat{O} V_{\bar{F} x y}}{\sqrt{\hat{\sigma}_{\bar{F} x}^{2} \hat{\sigma}_{\bar{F} y}^{2}}}
\end{aligned}
$$

em que: $C \hat{O} V_{P x y}$ e $C \hat{O} V_{\bar{F} x y}$ são as estimativas das covariâncias de progennes e fenotípica ao nível de médias respectivamente; $\hat{\sigma}_{P x}^{2}$ e $\hat{\sigma}_{P y}^{2}$ são as estimativas das variâncias genéticas de progênies $\mathrm{F}_{2: 3}$ e $\hat{\sigma}_{\bar{F} y}^{2}$ e $\hat{\sigma}_{\overline{F y}}^{2}$ as estimativas das variâncias fenotípicas ao nível de médias, dos caracteres $x$ e $y$ respectivamente.

Para as estimativas dos componentes de variância e dos coeficientes de herdabilidade ao nível de médias de progênies $F_{2: 3}$ foram construídos intervalos de confiança com $\alpha=95 \%$ de probabilidade (Burdick e Graybill, 1992). Para testar a hipótese de nulidade dos coeficientes de correlação genética $\left(r_{G x y}=0\right)$, empregou-se o método descrito por FALCONER e MACKay (1996). Para testar a hipótese de nulidade dos coeficientes de correlações fenotípicos $\left(r_{\bar{F} x y}=0\right)$ foi empregada a estatística $t$ de Student calculada, segundo SteEl e TorRIE (1980). 


\section{RESULTADOS E DISCUSSÃO}

A obtenção de estimativas de parâmetros genéticos é fundamental no melhoramento de plantas, uma vez que permite identificar a natureza da ação dos genes envolvidos no controle dos caracteres quantitativos e avaliar a eficiência de diferentes estratégias de melhoramento para a obtenção de ganhos genéticos e manutenção de uma base genética adequada nas populações.

Pelas análises de variâncias individuais, para todos os caracteres e em todos os ambientes, foram constatadas diferenças altamente significativas $(p \leq 0,01)$ entre progênies $F_{2: 3}$, à exceção do caráter prolificidade (PROL) no ambiente 9 , na população $\mathrm{D}$, e do caráter intervalo entre florescimentos (IF) no ambiente 2, na população $U$, indicando haver grande variabilidade genética para os diversos caracteres em ambas as populações (dados não apresentados).

As análises de variâncias conjuntas confirmaram a alta variabilidade genética de ambas as populações para os diversos caracteres avaliados (dados não apresentados). Esses resultados indicam ser possível obter ganhos com seleção nessas populações. As progênies da população $D$ tiveram maior variabilidade genética para os caracteres IF e SG, enquanto os demais caracteres foram mais variáveis para as progênies $F_{2: 3}$ oriundas da população $U$. A fonte de variação devido aos ambientes (A) e a interação progênies $\mathrm{x}$ ambientes $(\mathrm{P} \times \mathrm{A}$ ) foram altamente significativas $(p \leq 0,01)$ para todos os caracteres. As estimativas de $\mathrm{P} \times \mathrm{A}$ foram maiores para os caracteres PG, prolificidade, IF, e SG, e menores para FF, FM e $\mathrm{NRP}$, quando comparadas às estimativas de variância de progênies. A alta significância das fontes de variações devidas aos ambientes (A) e a interação $P x$ A sugerem, no primeiro caso, que os ambientes se comportaram diferentemente quanto aos valores médios das progênies para os diversos caracteres e no segundo, que o desempenho das progênies variou dependendo do ambiente de avaliação. A magnitude dos valores da interação $P$ x A sugere menor influência das condições ambientais para caracteres como FF, FM e NRP. JIANG et al. (1999), avaliando caracteres como PG, FM, FF, IF e NRP, relataram que neste último ocorreu a menor interação $\mathrm{P} \times \mathrm{A}$.

Os coeficientes de variação $(\mathrm{CV})$ das análises conjuntas foram, em geral, de magnitude baixa a mediana evidenciando boa precisão na tomada dos dados. Valores de CV menores que $10 \%$ foram observados para os caracteres FF, FM, NRP e SG. Para PG, PROL e IF foram constatados valores iguais a $16,53 \%, 14,62 \%, 62,17 \%$, para a população D e de $16,32 \%, 13,57 \%, 130,47 \%$, na população $U$, respectivamente (dados não apresentados). Os altos valores de $\mathrm{CV}$ observados para o caráter IF são resultados da própria natureza do caráter cuja média, formada por valores positivos e negativos, tende a ser muito baixa favorecendo valores elevados para $\mathrm{CV}$.

Na população D, o valor de média de progênies $\mathrm{F}_{2: 3}$ para o caráter produção de grãos foi 43,91 g planta $^{-1}\left(2,74 \mathrm{t} \mathrm{ha}^{-1}\right)$ com intervalo de variação de 21,83 g planta $^{-1}\left(1,36\right.$ tha $\left.^{-1}\right)$ a 64,35 g planta $^{-1}(4,02$ $\left.\mathrm{t} \mathrm{ha}^{-1}\right)$. Para os caracteres PROL, IF, FF, FM, NRP e SG, os valores de médias de progênies foram de, respectivamente, 0,70 espiga planta $^{-1}, 1,25 \mathrm{dia}, 64,78$ dias, 63,53 dias, 13,46 ramificações por pendão e nota de 3,44. Na população U, observou-se no caráter PG valor médio de 48,52 $\mathrm{g}_{\text {planta }}{ }^{-1}\left(3,03 \mathrm{t} \mathrm{ha}^{-1}\right) \mathrm{com}$ intervalo de variação de $19,47 \mathrm{~g}$ planta $^{-1}\left(1,22 \mathrm{t} \mathrm{ha}^{-1}\right)$ a 136,35 g planta $^{-1}\left(8,52 \mathrm{t} \mathrm{ha}^{-1}\right)$. Os valores de médias de progênies para os caracteres PROL, IF, FF, FM, NRP e SG, foram de 0,83 espiga planta ${ }^{-1}, 0,68 \mathrm{dia}, 69,96$ dias, 69,15 dias, 13,90 ramificações pendão ${ }^{-1}$ e nota de 4,13 respectivamente. Pela comparação dos intervalos de confiança, constatou-se que as médias das populações não diferiram quanto aos caracteres PG, PROL, IF e NRP. Na população D, o florescimento foi mais precoce e houve maior senescência de folhas e colmo comparada à população U. As médias de progênies $\mathrm{F}_{2: 3}$ evidenciaram baixa produção de grãos e baixa prolificidade, comportamento protândrico característico da espécie e pouco retardamento da senescência de folhas e colmo.

As estimativas de variâncias genéticas de progênies $\left(\hat{\sigma}_{P}^{2}\right)$ foram elevadas, bem próximas às estimativas de variância fenotípica e maiores que aquelas obtidas para os componentes $\hat{\sigma}_{P A}^{2}$ (Tabelas 1 e 2). Dentre os caracteres avaliados, produção de grãos foi de alta variabilidade genética. Na população $D$, $\hat{\sigma}_{P}^{2}$ para produção de grãos foi de $61,87\left(\mathrm{~g} \mathrm{planta}^{-1}\right)^{2}$, enquanto a variância para a interação progênies $x$ ambientes $\left(\hat{\sigma}_{P A}^{2}\right)$ foi de $32,05\left(\mathrm{~g} \text { planta }{ }^{-1}\right)^{2}$ o que equivale a aproximadamente $52 \%$ da variância genética de progênies. Para os demais caracteres $\hat{\sigma}_{P}^{2}$ variou entre 2,67 (dias) $^{2}$ para florescimento masculino a 12,13 (nota) ${ }^{2}$ para stay-green. Os valores $\hat{\sigma}_{P A}^{2}$ corresponderam a $75 \%, 20 \%, 10 \%, 8 \%, 8 \%$ e $57 \%$ da variação genética de progênies para os caracteres prolificidade, IF, FF, FM, NRP e SG respectivamente. Na população U, o valor de $\hat{\sigma}_{P}^{2}$ para produção de grãos $\left(267,18\left(\text { g planta }^{-1}\right)^{2}\right)$ foi bem maior que aquele obtido na população D. Para esse caráter, a estimativa da variância da interação progênies $x$ ambientes foi de 39,13 (g planta $\left.{ }^{-1}\right)^{2}$ o que corresponde a $15 \%$ da variância genética de progênies. Os valores $\hat{\sigma}_{P}^{2}$ para os demais caracteres variaram entre 3,76 (ramificações pendão $\left.{ }^{-1}\right)^{2}$ para NRP

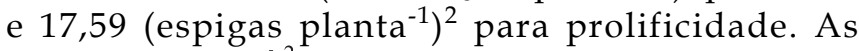
estimativas de $\hat{\sigma}_{P A}^{2}$ corresponderam a $25 \%, 45 \%, 9 \%$, 
13\%, 19\% e $73 \%$ da variância genética de progênies para os caracteres prolificidade, IF, FF, FM, NRP e SG respectivamente.

Comparando-se os valores dos intervalos de confiança para cada caráter entre as duas populações, observa-se que as estimativas dos componentes de variância para PG, FF, FM e NRP foram, em geral, maiores na população $U$, enquanto para os caracteres IF e SG essas estimativas foram, em geral, maiores na população $\mathrm{D}$. Na população $\mathrm{U}$, as estimativas de $\hat{\sigma}_{P}^{2}$ para PG e PROL foram cerca de quatro vezes maior que aquelas obtidas para a população D; esse resultado reforça a idéia de maior variabilidade genética para ambos os caracteres na população $U$. No presente trabalho, as duas populações estudadas foram desenvolvidas a partir do cruzamento entre linhagens divergentes oriundas de grupos heteróticos distintos. Contudo, as linhagens endogâmicas L20-01F e L02-03D, que originaram a população D, foram escolhidas pela alta divergência em relação ao teor de óleo, ao passo que, o cruzamento que deu origem à população U (L14-04B x L08-05F) foi selecionado com base na capacidade específica de combinação das linhagens genitoras. Ou seja, nesse cruzamento espera-se grande complementaridade entre genes para inúmeros caracteres, principalmente, produção de grãos e prolificidade. Esse fato pode justificar a maior variabilidade observada nas progênies $F_{2: 3}$ oriundas dessa população, como verificado pelos maiores intervalos de variações para médias e maiores estimativas de componentes de variância genética entre progênies, principalmente em relação aos caracteres produção de grãos e prolificidade.

Os intervalos de confiança para os componentes de variância $\hat{\sigma}_{P}^{2}$ e $\hat{\sigma}_{P A}^{2}$ indicaram que as estimativas diferem de zero, sugerindo que tenham contribuído para a variação fenotípica dos caracteres. Observaram-se para $\hat{\sigma}_{P}^{2}$ valores bem próximos àqueles obtidos para a variância fenotípica e, em geral, maiores que aquelas do componente $\hat{\sigma}_{P A}^{2}$; essas diferenças entre progênies seriam decorrentes, sobretudo de sua constituição genética. Entretanto, estimativas de $\hat{\sigma}_{P A}^{2}$ foram de magnitude elevada para vários caracteres. Na população D, o componente $\hat{\sigma}_{P A}^{2}$ para produção de grãos equivaleu a mais de $50 \%$ da variação estimada para $\hat{\sigma}_{P}^{2}$. Esse resultado está de acordo com o comportamento esperado para o caráter, em que boa parte da sua variação fenotípica tem sido atribuída a influências ambientais. A alta variabilidade genética e o menor número de ambientes influenciaram na contribuição de $\hat{\sigma}_{P A}^{2}$ para a variância fenotípica de PG na população U. Os caracteres FF, FM e NRP tiveram, proporcionalmente, as menores estimativas de $\hat{\sigma}_{P A}^{2}$, indicando pouco influência das condições ambientais sobre eles.
Nas estimativas dos coeficientes de herdabilidade no sentido amplo de médias de progênies $\mathrm{F}_{2: 3}\left(\hat{h}_{\bar{P}}^{2}\right)$, os valores foram elevados para todos os caracteres. Na população D, $\hat{h}_{\bar{P}}^{2}$ variou de $73,52 \%$ no caráter prolificidade a $94,12 \%$ para florescimento masculino. Na população $U, \hat{h}_{\bar{P}}^{2}$ variou de $76,58 \%$ para o caráter intervalo entre florescimentos a $95,88 \%$ para florescimento feminino (Tabelas 1 e 2). As estimativas de herdabilidade obtidas são de magnitude elevada, particularmente, em relação ao caráter produção de grãos, onde $\hat{h}_{\bar{P}}^{2}$ foi de $86,79 \%$ e $94,84 \%$ para as populações D e U respectivamente. Valores equivalentes ou próximos aos observados no presente estudo têm sido constatados para NRP, FF e FM, sendo pouco freqüentes para os demais caracteres, principalmente PG. Hallauer e Miranda Filho (1988), com base em estimativas de herdabilidade entre parcelas de 99 estudos, constataram um valor médio de herdabilidade para o caráter produção de grãos igual a $18,7 \%$.

Os valores elevados dos coeficientes de herdabilidade obtidos para os caracteres são, provavelmente, decorrentes do grande número de ambientes em que as progênies foram avaliadas (nove ou sete) e de sua grande variabilidade genética. Estimativas de herdabilidade de alta magnitude podem ser indicativas que: a) um pequeno número de genes controla o caráter (complexidade biológica); b) pouco da variação do caráter é devido ao ambiente ou erro experimental e/ou c) as diferenças relativas entre valores genotípicos são pouco influenciadas pelo ambiente (interação genótipos $x$ ambientes é pouco expressiva) (FLINT-GARCIA et al., 2005). A maior estabilidade às variações ambientais e, provavelmente, a menor complexidade podem ter contribuído para os altos valores de herdabilidade em caracteres como NRP. Estimativas de herdabilidade auxiliam o melhoramento em determinar a alocação de recursos necessários para selecionar um caráter de interesse e adquirir máximo ganho genético utilizando menos tempo e recursos (SMAlley et al., 2004). A herdabilidade pode assim, indicar quantas repetições e qual tipo de delineamento experimental seriam necessários para minimizar erros experimentais. Estimativas de herdabilidade são importantes também em trabalhos voltados ao mapeamento de QTLs uma vez que estas indicam a precisão das estimativas dos valores genotípicos médios que serão usados nas análises de mapeamento (FLINT-GARCIA et al., 2005). O grande número de ambientes e de progênies avaliadas, conseqüentemente elevado número de graus de liberdade, permitiram detectar estimativas significativas de correlação fenotípica de baixa magnitude (até 0,13$)$. Todavia, essa significância deve ser interpretada com cautela nesses casos. 


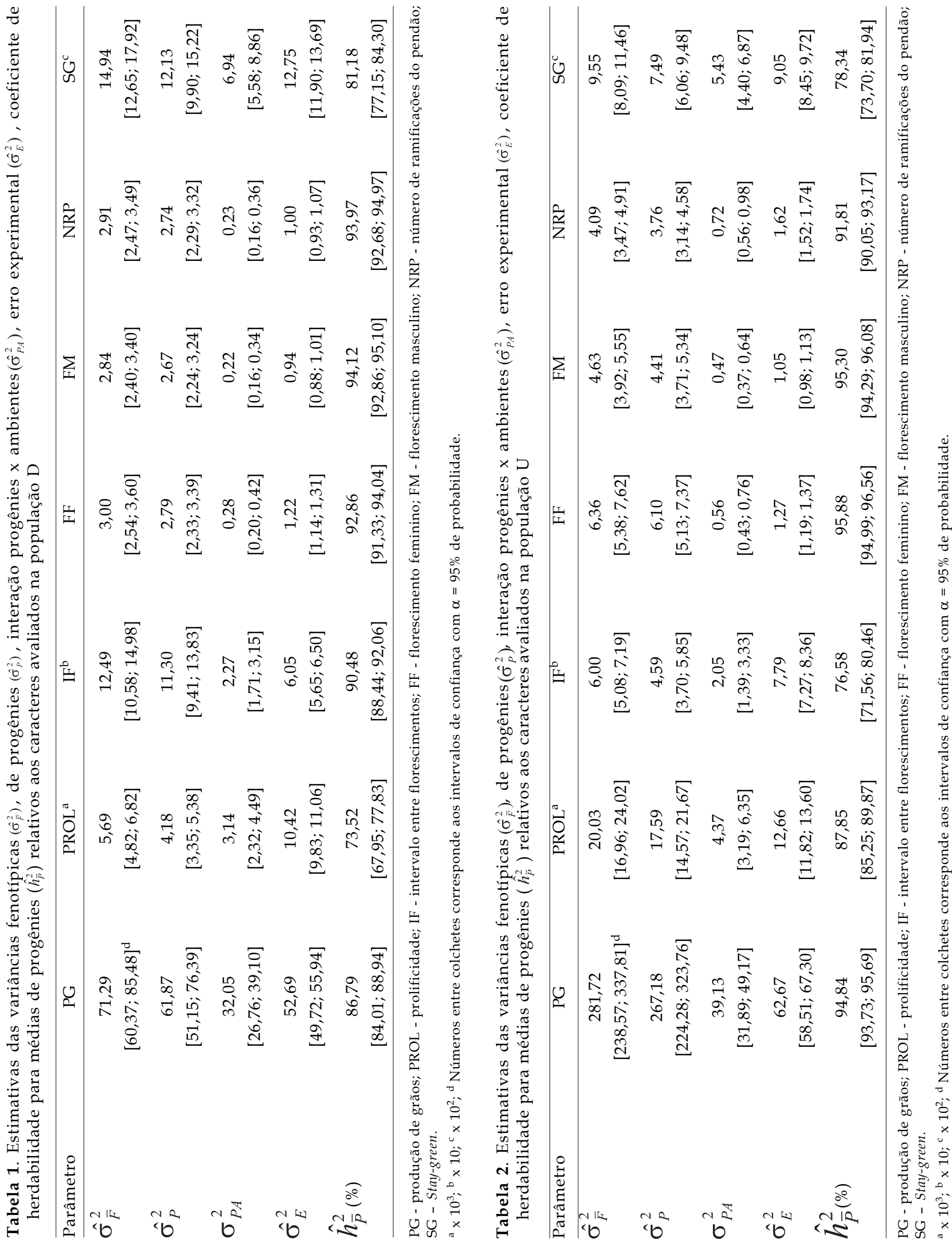


Uma correlação entre dois caracteres $x$ e $y$, de baixa magnitude indica ser a proporção da variável resposta ( $y$ ou $x$ ), explicada por um modelo que assume uma relação linear entre $x$ e $y$, menor que $2 \%$ $\left(r^{2}=0,0169\right)$. O conhecimento da associação entre caracteres é de grande importância nos trabalhos de melhoramento, principalmente, se na seleção de um desses caracteres houver dificuldades em razão da baixa herdabilidade e/ou tenha problemas para medição e identificação. Nesses casos, a seleção indireta, com base na resposta correlacionada, pode levar a progressos mais rápidos que a seleção direta para o caráter desejado.

Os maiores valores de correlação fenotípica e genética $\left(0,94^{* *}\right.$ e $0,95^{* *}$ respectivamente) foram obtidos entre os caracteres FF e FM na população U. Em geral, no caráter NRP, houve pouca relação com os demais caracteres avaliados (Tabela 3). Na população D, o caráter produção de grãos apresentou estimativas da correlação fenotípica $\left(\hat{r}_{\bar{F}}\right)$ positiva e altamente significativa $(P \leq 0,01)$ apenas com prolificidade $(0,82)$, enquanto estimativas negativas e altamente significativas foram observadas com os caracteres IF $(-0,30)$, FF $(-0,43)$, FM $(-0,24)$ e SG $(-0,46)$. Correlações genéticas $\left(\hat{r}_{G}\right)$ altamente significativas envolvendo produção de grãos e os demais caracteres foram constatadas para PROL $(0,88)$, FF $(-0,44)$ e SG $(-0,50)$. $\mathrm{Na}$ população $\mathrm{U}$, estimativas altamente significativas de $\hat{r}_{\bar{F}}$ envolvendo PG foram observadas para os caracteres PROL $(0,77)$, IF $(-0,28)$, FF $(-0,74)$ e FM $(-0,71)$ e significativas com os caracteres NRP $(0,13)$ e SG $(-0,13)$. Nessa população, no caráter PG observou-se correção genética altamente significativa com PROL $(0,79)$, FF $(-0,76)$ e FM $(-0,74)$ e pouca associação genética com IF e, principalmente, NRP e SG.

Estimativas de $\hat{r}_{\bar{F}}$ envolvendo os demais caracteres foram, em geral, significativas, exceção daquelas para NRP. Entre esses caracteres, as estimativas de $\hat{r}_{G}$ foram, em geral, não-significativas. Estimativas positivas e significativas de $\hat{r}_{G}$ em ambas as populações foram constatadas apenas entre IF $x \mathrm{FF}$ e FF $x$ FM. Estimativas significativas e negativas de $\hat{r}_{G}$ foram obtidas entre os caracteres PROL x FF $(-0,50)$ e PROL x FM $(-0,35)$ na população $D$, e entre PROL $x$ IF $(-0,53)$, PROL x FF $(-0,69)$, PROL x FM $(-0,59)$ e IF $x$ SG $(-0,37)$, na população $U$.

Os resultados para correlação entre PG e PROL estão de acordo com aqueles relatados na literatura, que suportam fortes evidências de correlação positiva entre os dois caracteres. Entre PG e caracteres como NRP e IF, as estimativas de correlação genética foram em geral não-significativas. Trabalhos têm relatado correlação normalmente alta e significativa entre PG e IF (Agrama e Moussa, 1996; KAMARA et al., 2003).

Tabela 3. Valores e significâncias dos coeficientes de correlação genética $\left(\hat{r}_{G}\right)$, acima da diagonal, e fenotípica $\left(\hat{r}_{\bar{F}}\right)$, abaixo da diagonal, entre diversos caracteres em duas populações de milho tropical

\begin{tabular}{|c|c|c|c|c|c|c|c|c|}
\hline Populações & & PG & PROL & IF & FF & FM & NRP & SG \\
\hline $\mathrm{D}$ & PG & - & $0,88^{* *}$ & $-0,31^{\mathrm{ns}}$ & $-0,44^{* *}$ & $-0,25^{\mathrm{ns}}$ & $0,11^{\mathrm{ns}}$ & $-0,50^{* *}$ \\
\hline $\mathrm{U}$ & & & $0,79^{* *}$ & $-0,32^{\text {ns }}$ & $-0,76^{* *}$ & $-0,74^{* *}$ & $0,12^{\mathrm{ns}}$ & $-0,12^{\mathrm{ns}}$ \\
\hline $\mathrm{D}$ & PROL & $0,82^{* *}$ & - & $-0,25^{\mathrm{ns}}$ & $-0,50^{* *}$ & $-0,35^{*}$ & $-0,06^{\mathrm{ns}}$ & $-0,14^{\mathrm{ns}}$ \\
\hline $\mathrm{U}$ & & $0,77^{* *}$ & & $-0,53^{* *}$ & $-0,69^{* *}$ & $-0,59^{* *}$ & $-0,11^{\text {ns }}$ & $0,06^{\text {ns }}$ \\
\hline $\mathrm{D}$ & IF & $-0,30^{* *}$ & $-0,23^{* *}$ & - & $0,35^{*}$ & $-0,29^{\text {ns }}$ & $-0,02^{\text {ns }}$ & $0,31^{\mathrm{ns}}$ \\
\hline $\mathrm{U}$ & & $-0,28^{* *}$ & $-0,45^{* *}$ & & $0,53^{* *}$ & $0,23^{\mathrm{ns}}$ & $0,25^{\mathrm{ns}}$ & $-0,37^{*}$ \\
\hline $\mathrm{D}$ & FF & $-0,43^{* *}$ & $-0,46^{* *}$ & $0,37^{* *}$ & - & $0,79^{* *}$ & $-0,07^{\mathrm{ns}}$ & $-0,13^{\text {ns }}$ \\
\hline $\mathrm{U}$ & & $-0,74^{* *}$ & $-0,66^{* *}$ & $0,48^{* *}$ & & $0,95^{* *}$ & $-0,10^{\text {ns }}$ & $-0,20^{\mathrm{ns}}$ \\
\hline $\mathrm{D}$ & FM & $-0,24^{* *}$ & $-0,32^{* *}$ & $-0,29^{* *}$ & $0,79^{* *}$ & - & $-0,06^{\mathrm{ns}}$ & $-0,33^{\mathrm{ns}}$ \\
\hline $\mathrm{U}$ & & $-0,71^{* *}$ & $-0,56^{* *}$ & $0,18^{* *}$ & $0,94^{* *}$ & & $-0,20^{\mathrm{ns}}$ & $-0,12^{\text {ns }}$ \\
\hline $\mathrm{D}$ & NRP & $0,11^{\mathrm{ns}}$ & $-0,04^{\mathrm{ns}}$ & $-0,02^{\mathrm{ns}}$ & $-0,08^{\mathrm{ns}}$ & $-0,07^{\mathrm{ns}}$ & - & $-0,15^{\mathrm{ns}}$ \\
\hline $\mathrm{U}$ & & 0,13 * & $-0,08^{\mathrm{ns}}$ & $0,22^{* *}$ & $-0,11^{\mathrm{ns}}$ & $-0,20^{* *}$ & & $-0,06^{\mathrm{ns}}$ \\
\hline $\mathrm{D}$ & SG & $-0,46^{* *}$ & $-0,11^{\mathrm{ns}}$ & $0,27^{* *}$ & $-0,11^{\mathrm{ns}}$ & $-0,30^{* *}$ & $-0,14^{*}$ & - \\
\hline $\mathrm{U}$ & & $-0,13^{*}$ & $0,04^{\mathrm{ns}}$ & $-0,28^{* *}$ & $-0,18^{* *}$ & $-0,10^{\mathrm{ns}}$ & $-0,05^{\mathrm{ns}}$ & \\
\hline
\end{tabular}

PG - produção de grãos; PROL - prolificidade; IF - intervalo entre florescimentos; FF - florescimento feminino; FM - florescimento masculino; NRP - número de ramificações do pendão; SG - Stay-green. ns, ${ }^{*},{ }^{* *}$ - não significativo, significativo a $5 \%$ e $1 \%$ de probabilidade, respectivamente, pelo teste $t$. 
A falta de associação genética entre esses dois caracteres no presente estudo pode ser decorrente das boas condições de umidade em que os experimentos foram avaliados, implicando em variações no caráter IF que pouco influenciaram a produtividade. As boas condições experimentais e pendões com número pequeno de ramificações podem ter minimizado a competição entre espiga e pendão e reduzido os efeitos de NRP na produção de grãos. A correlação nãosignificativa entre PG e SG para a população U poderia ser função da falta de ocorrência de estresse hídrico, principalmente, no período de pós-florescimento e enchimento de grãos.

As estimativas da correlação genética entre os caracteres relacionados ao florescimento e o caráter prolificidade foram em geral significativas. Com esses resultados observa-se que a seleção com base em caracteres como prolificidade, tenderia a elevar a produção de grãos, aumentando a precocidade e mantendo ou reduzindo o intervalo entre florescimentos. Pelos resultados verifica-se que, sob condições de estresse hídrico, a herdabilidade para prolificidade tem-se mantido constante ou até mesmo aumentado (BolAÑos e EDMEADES, 1996) e a seleção direta para o caráter nessas condições poderia promover maiores ganhos indiretos na produção de grãos. Os caracteres FF e FM tiveram pouca interação com ambiente e correlação genética alta e significativa com PG e PROL. A seleção para precocidade tenderia a ser mais precisa que para os demais caracteres e poderia aumentar indiretamente a produção de grãos e a prolificidade, reduzindo o intervalo entre florescimentos. A seleção para menor FF e FM poderia, conseqüentemente, aumentar a tolerância ao estresse hídrico em ambas as populações pelo aumento da prolificidade e redução no intervalo entre florescimento. A seleção de plantas com maior retardamento da senescência não tende a promover alteração na produção de grãos para a população U. Entretanto, a associação entre esses caracteres é mais consistente sob estresse hídrico e foi comprovada pela alta significância de $\hat{r}_{G}$ na população $\mathrm{D}$. O retardamento da senescência (aumento do stay-green) tende a promover maior tolerância a déficits hídricos sendo assim desejável sua seleção em ambas as populações.

\section{CONCLUSÃO}

Os resultados do presente trabalho sugerem que o desenvolvimento de cultivares com alta produção de grãos e boa tolerância a estresses hídricos poderia ser obtido pela utilização de índices de seleção que incluam, além de PG, caracteres como PROL, FF e SG na seleção de progênies sob condições normais de umidade.

\section{AGRADECIMENTOS}

Os autores agradecem o suporte financeiro durante o desenvolvimento deste trabalho à Coordenação de Aperfeiçoamento de Pessoal de Nível Superior (CAPES), ao Conselho Nacional de Desenvolvimento Científico e Tecnológico $(\mathrm{CNPq})$ e à Universidade de São Paulo.

\section{REFERÊNCIAS}

AGRAMA, H.A.; MOUSSA, M.E. Mapping QTLs in breeding for drought tolerance in maize (Zea mays L.) Euphytica, Wageningen, v. 91, n. 1, p. 89-97, 1996.

BÄNZINGER, M.; EDMEADES, G.O.; BECK, D.; BELLON, M. Breeding for drought and nitrogen stress tolerance in maize: from theory to practice. Mexico, D.F.: CIMMYT. 2000. 68p.

BOLAÑOS, J.; EDMEADES, G.O. The importance of the anthesis-silking interval in breeding for drought tolerance in tropical maize. Field Crops Research, Amsterdam, v. 48, n. 1, p. 65-80, 1996.

BURDICK; R.K.; GRAYBILL, F.A. Confidence intervals on variance components. New York: Marcel Dekker, 1992. v. $127,211 \mathrm{p}$.

DURÃES, F.O.M.; dos SANTOS, M.X.; GAMA, E.E.G.; MAGALHÃES, P.C.; ALBUQUERQUE, P.E.P.; GUIMARÃES, C.T. Fenotipagem associada à tolerância a seca em milho para uso em melhoramento, estudos genômicos e seleção assistida por marcadores. Sete Lagoas: EMBRAPA, 2004. 17p. (Circular Técnica, n.39)

FALCONER, D.S.; MACKAY, T.F.C. Introduction to Quantitative Genetics. 4. ed. London: Longman Scientific e Technical, 1996. 464 p.

FLINT-GARCIA, S.A.; THUILLET, A.C.; YU, J.M.; PRESSOIR, G.; ROMERO, S.M.; MITCHELL, S.E.; DOEBLEY, J.; KRESOVICH, S.; GOODMAN, M.M.; BUCKLER, E.S. Maize association population: a high-resolution platform for quantitative trait locus dissection. Plant Journal, Oxon, v. 44, n. 6, p. 1054-1064, 2005.

HALLAUER, A.R.; MIRANDA FILHO, J.B. Quantitative genetics in maize breeding. 2.ed. Ames: Iowa States University Press, 1988. 468 p.

INSTITUTO BRASILEIRO DE GEOGRAFIA E ESTATÍSTICA IBGE. Indicadores agropecuários 1996-2003. Rio de Janeiro: IBGE, 2004. 68 p.

JIANG, C.; EDMEADES, G.O.; ARMSTEAD, I.; LAFITTE, H.R.; HAYWARD, M.D.; HOISINGTON, D. Genetic analysis of adaptation differences between highland and lowland tropical maize using molecular markers. Theoretical and Applied Genetics, New York, v. 99, n. 7-8, p. 1106-1119, 1999. 
KAMARA, A.Y.; MENKIR, A.; BADU-APRAKU, B.; IBIKUNLE, O. Reproductive and stay-green trait reponses of maize hibrids, improved open-pollinated varieties and farmers' local varieties to terminal drought stress. Maydica, Bergamo, v. 48, n. 1, p. 29-37, 2003.

MANGOLIN, C.A.; de SOUZA Jr., C.L.; GARCIA, A.A.F.; GARCIA, A.F.; SIBOV, S.T.; SOUZA, A.P. Mapping QTLs for kernel oil content in a tropical maize population. Euphytica, Wageningen, v. 137, n. 2, p. 251-259, 2004.

RIBAUT, J.M.; HOISINGTON, D.A.; DEUTSCH, J.A.; JIANG, C.; GONZALEZ-DE-LEON, D. Identification of quantitative trait loci under drought conditions in tropical maize. 1. Flowering parameters and the anthesis-silking interval. Theoretical and Applied Genetics, New York, v. 92, n. 7, p. 905-914, 1996.

RIBAUT, J.M.; JIANG, C.; GONZALEZDELEON, D.; EDMEADES, G.O.; HOISINGTON, D.A. Identification of quantitative trait loci under drought conditions in tropical maize .2. Yield components and marker-assisted selection strategies. Theoretical and Applied Genetics, New York, v. 94, n. 6-7, p. 887-896, 1997.
SANTOS, M.X.; ANDRADE, C.L.T.; OLIVEIRA, A.C.; LEITE, C.E.P.; CARVALHO, H.W.L.; GAMA, E.E.G.; PACHECO, C.A.P.; GUMARÃES, P.E.O.; PARENTONI, S.N. Comportamento de híbridos de milho selecionados e não selecionados para ASI sob estresse de água no florescimento e no enchimento de grãos. Revista Brasileira de Milho e Sorgo, Sete Lagoas, v. 2, n. 2, p.71-81, 2003.

SMALLEY, M.D.; DAUB, J.L.; HALLAUERS, A.R. Estimation of heritability in maize by parent-offspring regression. Maydica, Bergamo, v. 49, n. 3, p. 221-229, 2004.

SOUZA JUNIOR, C.L.; SANTOS, M.X.; MAGNAVACA, R.; GAMA, E.E.G. Estimativas de parâmetro genéticos na interpopulação de milho BR-105 x BR-106 e suas implicações no melhoramento. Pesquisa Agropecuária brasileira, Brasília, v. 28, n. 4 , p. $473-479,1993$.

STEEL, R.G.D.; TORRIE, J.H. Principles and procedures of statistics: a biometrical approach. 2.ed. New York: McGrawHill, 1980. 631p. 